\title{
Developing community-based engagement in Smart Cities: A design-computational thinking approach
}

\author{
Chien-Sing Lee \\ Department of Computing and Information Systems, \\ Sunway University, Malaysia. \\ chiensingl@sunway.edu.my
}

\author{
K. Daniel Wong \\ Daniel Wireless Software Pte Ltd., Singapore. \\ dwong@danielwireless.com
}

\begin{abstract}
Smart Cities development has progressed rapidly with Internet of Things (IoT), ambient intelligence and increasingly, crowdsourcing. Engaging the community thus plays a key role in developing meaningful communal growth along with other stakeholders. This paper briefly presents a pilot study on developing computational perspectives for community-based engagement and innovations in Smart Cities for the young and thereafter, to explore possibilities of engaging seniors in self and community development, and the young and old in community-based engagement and possibly in the future, the development of viable values-based innovations in information systems.
\end{abstract}

Keywords- community engagement, service innovation and management, design thinking, computational thinking, Smart Cities

\section{INTRODUCTION}

Science, Technology, Engineering and Mathematics (STEM) is crucial in inculcating cultures of innovation. Hence, aiming to increase competitiveness in science and technology development, many governments aim to increase the percentage of children and youth taking up STEM education and career. Research shows that STEM involves the development of problem-solving or critical thinking skills, including evaluation of usefulness and relevance to the context.

With advancements in technology, three paradigm shifts have come to the fore. Among these, codesign/creation is emphasized with looser institutional boundaries and sense of ownership. These paradigm shifts create greater opportunities for knowledge building, deeper purposeful learning, in search of structure and meaning. However, the learning curve for some, may be steeper as the domain widens. This requires varied methodologies to increase cognitive access and subsequently, improve learning outcomes.

For Science/computing, after numerous analyses on Scratch, [1] provide some focus towards the development of STEM. Corresponding with [2]'s computational thinking, where computing extends coding to ideation and its application to authentic problems, [1] recommend designing instruction based on computational concepts (the concepts designers engage with as they program, for example iteration, loops), computational practices, i.e., the practices designers develop as they engage with the concepts, for example debugging projects or remixing others' work, abstracting and modularizing), and computational perspectives (the perspectives designers form about the world around them and about themselves, for example expressing, connecting, questioning). We conjecture that this is more likely to result in elegance in computational design and processes.

\section{A. Objectives}

In a series of studies in the creative industries in Universiti Tunku Abdul Rahman, Malaysia [3], we explored how to integrate design thinking [4, 5] with Problem-based Learning-Learning-by-Design [6] to develop social innovations (sustainability) among youths. Subsequently, in Sunway University, we explored design thinking-based entrepreneurial narrative framework for the development of innovations also targeted at sustainability, but grounded in Information Systems [7]. Subsequently, extending from this, some preliminary findings involving the role of design thinking and computational thinking in relation with agile methodology and user experience have been reported in [8].

Across all projects, design thinking [9, 5], user experience and agile methodology are applied for the following reasons:

a) The waterfall model facilitates systematic knowledge building as each phase is a building block of the next phase. By facilitating strong control over the process, the waterfall model creates clarity to what is being developed. Hence, project planning and communication with clients become easier. The sequence of steps however, is linear and the user comes in at the end.

b) The more popular agile development process enables faster progress. By including the user through joint application development/participatory design, agile design and development eliminates elaborate specifications for user interfaces and decision support functions, avoiding following a fixed plan to only what is relevant and crucial.

Thus far, our work has been in structured formal learning environments. In this paper, we continue with similar lines of thought but extend it to include both young and old, towards unstructured informal learning environments. We would like to build community-based engagement for two reasons:

a) to encourage more participation towards mashable innovations for Smart City communities, where entrepreneurship is liberalized and strategic collaborations can lead to positive results;

b) to encourage more peer/intergenerational interactions (since identity can be anonymized) to encourage social and cognitive engagement and possibly mutual learning. 
We contextualize inquiry and interactions within the context of how [10]'s media-model framework can support the use of media and the extension from STEM to possibly STEAM. The idea of media as building blocks as well as experimental ideation tools is supported by various research such as Scratch by MIT.

The media-model framework functions as a cognitive prosthesis or building blocks; translating from concepts to media. Aiming to discover rigorous frameworks to make informed choices during product or software development, the media-models framework through different resolutions and abstractions, encourages students/users to gain new insights in terms of statement of intentions, asking process questions, envisioning user scenarios, enacting user scenarios, combining metaphors and experiencing Aha moments, requiring different cognitive strategies in communicating.

\section{B. Research questions}

As mentioned above, we are interested to investigate media-model case studies in line with [10]'s framework, [11]'s motivation theory and in line with inclusive design. Instead of increasing scaffolding due to the lack of structure, we removed these explicit scaffolds and include gamification. Hence, our research questions are:

1. will gamified curation and co-design increase fun and subsequently increase interest to learn STEM?

2. can the planning-reflective nature of gamification function as embedded learning scaffolds?

3. can these applications/findings be applied to other target groups such as seniors?

Our simplified research model for unstructured informal environments is illustrated in Fig. 1 below.

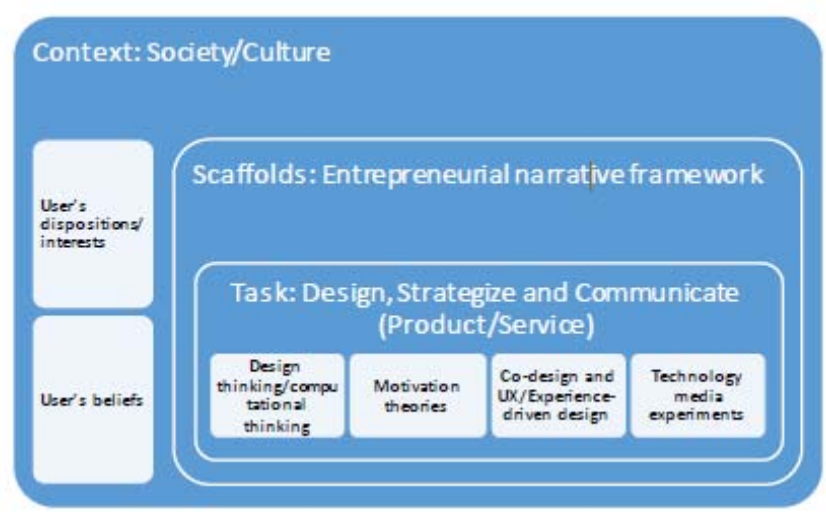

Fig. 1. Research model

The outline of this paper is as follows. We first present related work. This is followed by methodology, the case study on youth, findings, discussion and conclusion.

\section{RELATED WORK}

We will now review three thrusts to this work: design thinking, creativity and gamification to derive implications to the design of systems for inclusive design. [9]'s design thinking study highlights the interdependency and iterative alignment between problem and solution space.

Emphasizing that designers need to achieve a multiperspective comprehension of a complex and ambiguous problem, many design thinking studies have proven the usefulness of design thinking to Information Technology development.

Gamification has evidenced mixed responses. Some gamification studies such as by [12], indicate that gamification has the potential to provide positive effects. However, these effects differ based on the context in which the gamification is being implemented, and the characteristics of the users. However, studies by [13] indicate the need for more caution.

In two gamification studies $[14,15]$, the problem addressed is the development of an innovation mindset and artefacts through [1]'s computational perspectives enabled via experimentations with augmented reality (Fig. 2) and crafts (Figs. 3, 4) respectively. For systems evaluations, the Technology Acceptance Model [16] is used.

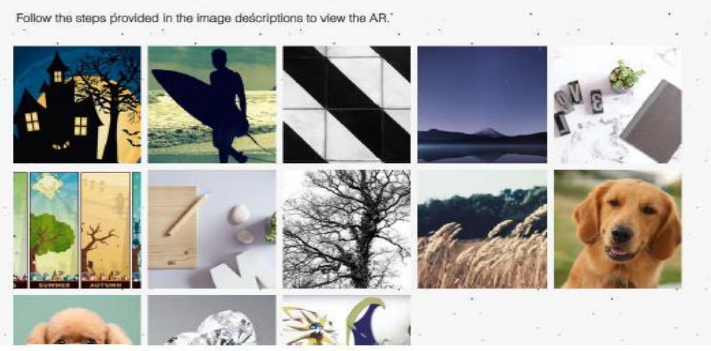

Fig. 2. Augmented-reality-based sharing

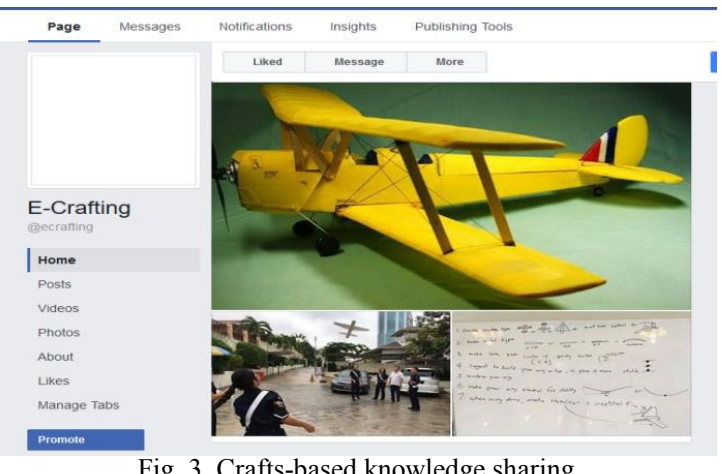

Fig. 3. Crafts-based knowledge sharing

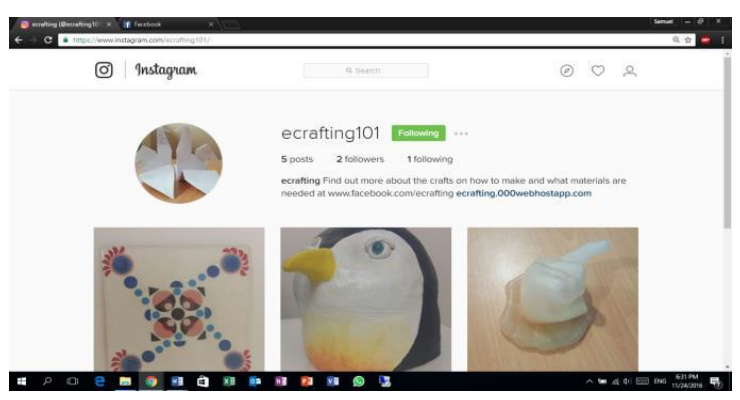

Fig. 4. Sample screen shot on craft

Findings are promising and positively answer research questions 1 and 3. Furthermore, we find that the planningbased nature of gamification if fully successful, can function as embedded learning scaffolds to a certain extent. Further details are in a journal paper under review. The journal paper details and explains the groundings and identification of factors which encourage meaningful interactions/ innovation, among the youth groups for these two applications. 
We hope that with continued use, students may use and form possible synergies between Science and Art to enrich the \#mydigitalmaker outcomes. Next, we provide an example of inclusive design, beginning first with background information in Sections III A, B, and C.

\section{COMMUNITY ENGAGEMENT FOR THE SENIORS AND THEIR CAREGIVERS}

World Health Organization's (WHO) International Classification of Functioning, Disability and Health (ICF) [17] categorizes healthcare for aging with and into disability into several categories as illustrated in Fig. 5.

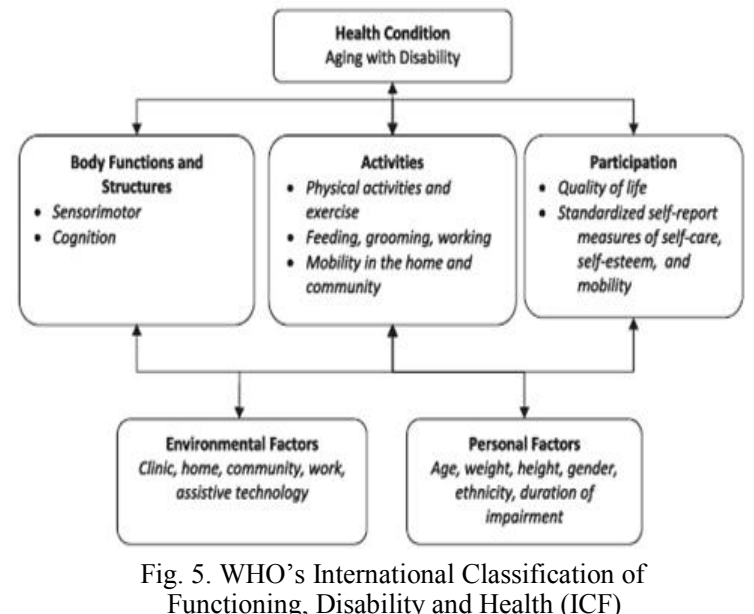

The role of social engagement as a significant determiner in an age-friendly environment is highlighted by in a pilot study in a small city in Malaysia, Melaka, among seniors [18]. For this pilot, we focus on another group, i.e., seniors with Mild Cognitive Impairment. Currently, our target users are clients of the Alzheimer's Disease Foundation of Malaysia (ADFM). These clients are at the mild stage of Alzheimer's, suffering from Mild Cognitive Impairment (MCI) as assessed by geriatricians and medical personnel affiliated to the ADFM periodically.

[19] argue that Alzheimer's is a medically and psychosocially understandable and manageable problem and thus, we should focus on minimizing the symptoms and related dementias instead of focusing on searching for a cure. The first step towards this change in perspective is to approach patient care by systematically compensating functional losses of dementia by associating care-giving actions and environments to brain dysfunctions. Considering the neuropathology of the disease would then increase the likelihood of improved quality of life (delayed institutionalization and decrease in the progression of the disease).

Evidence of social decline is supported by [20]'s longitudinal investigation. They find that there is a relationship between low levels of social engagement in midlife and late life with the risk of incident dementia after assessing patients' social engagement at midlife and late life. Findings indicate no correlation between midlife social engagement and risk of dementia. However, for late life, there is a significant increased risk of dementia for those at the lowest quartile of social engagement.

\section{A. Scope and objectives}

We scope our research to designing gamification for the seniors' fun and entertainment during their leisure personal/family time, and connecting them with like minded friends - just to make them happier - if possible. The rationale is we would like to design for personhood [21] as this implies more holistic primary care.

We hypothesize that cognitive and logical abilities decline slower than memory. Thus, we are interested to investigate which factors would be more significant in driving social and cognitive engagement among the elderly in a community-based environment.

\section{B. Preferences}

A questionnaire survey consisting of five questions is carried out to identify their interests and views. Participation in the study is totally voluntary. Seven clients participated. The findings from a preliminary questionnaire indicate that many are interested in jigsaw (22), mah-jong (17), craft (16), snake and ladder (15), bingo (14). Findings also indicate that they are interested to maintain social ties with family, relatives and friends, supporting [18]'s pilot study, though in a different state in Malaysia and among non-MCI seniors. This will be the main motivation for social engagement.

\section{Low fidelity crafting}

Due to their interest in and familiarity with crafts, an activity based on design thinking-based semiotics is carried out to enable the clients to express themselves. An example of outcomes is shown in Fig. 6. This activity has also enabled us to categorize the ADFM's clients into two preliminary groups of clients based on two key characteristics in the use of the given shapes. Further elaboration is in [22].
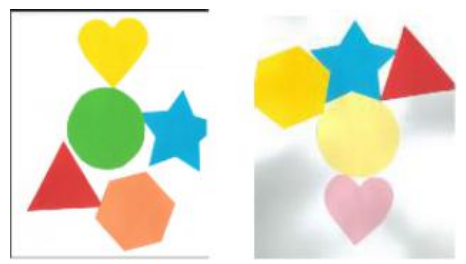

Fig. 6. Sample craft by Group 1 (left) and Group 2 (right)

\section{Receptivity to such collaborative activities, towards greater social inclusivity}

The ADFM is receptive to the idea of using the gamified Facebook website (content adapted to their needs). We conjecture that we can use the gamified augmented reality and art-craft portal for younger elderlies (between 50-65 years old).

For the older elderlies in the ADFM, success in every attempt is crucial and the ADFM's clients are apprehensive when it comes to using mobile apps. Hence, we can use the portals for the ADFM's client's caregivers but for the ADFM's clients, retain non-digital crafts. We believe age is not a determiner. Rather, the level of MCI 
is. Hence, we can design and develop Web-based solutions/mobile apps involving games they are familiar with mapped to the findings from the youth gamification studies for people of different age groups, even for youths.

\section{E. Preliminary findings on Web-mobile apps for seniors}

Mobile devices empower. However, it is not a panacea. We face design challenges in the earlier two capstone projects in terms of how to embed affordances to function as self-regulatory scaffolds. In two subsequent capstone projects, we embed gamification through embedded affordances. We decide on consistency in interface and interaction design for the first project and for the second project, metaphor.

Another consideration is [23]'s theory of fun. [23] analogizes people as amazing pattern-matching machines. He points out that once we recognize a pattern, we would usually seek to see it recur. We conjecture that these mechanics can also be used in designing instructional framework and design challenges as learning is experimental/ game-like and learners are experimenters /players.

Based on design thinking and object-oriented analysis and design, two projects were designed and developed. In the first capstone project [24], a mobile app is designed and developed based on our research model. Images are retrieved based on the above preferences to increase stimuli, interest, exposure and strengthen associative memory through a game. The traditional bingo algorithm is applied mapped to our winning patterns at the backend but the "assets" /media objects change from numbers (Bingo 1) to images (Bingo 2) for a user-vs. computer game. In the third game, the same "assets" are used for a single player memory game.

Another capstone project is on Web and augmentedreality-enhanced mobile - based exergaming [25]. Users can choose from their interests (travelling, cooking, dancing or miscellaneous) upon logging in. There are activities there such as dances specifically for old people to help keep their balance and prevent falls. Images can be uploaded or connected from the bingo game. This Web application also has a forum where users can discuss and the most number of likes at any of the travelling, cooking or dancing or miscellaneous categories will be featured in the respective forum pages of the Web portal.

Sample screenshots are in Figs. 7 and $8 \mathrm{a}, \mathrm{b}$. User testing results on 10 active seniors (without $\mathrm{MCI}$ ) are positive as exemplified in [24].

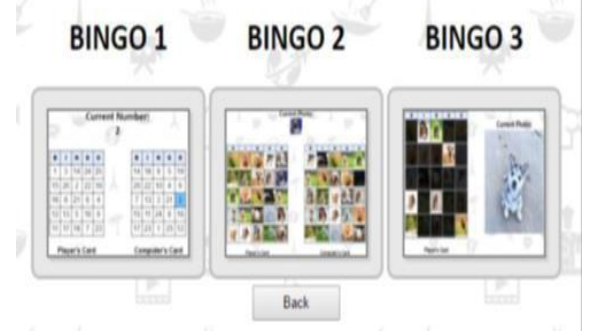

Fig. 7. Three variants of bingo game (Web/mobile)

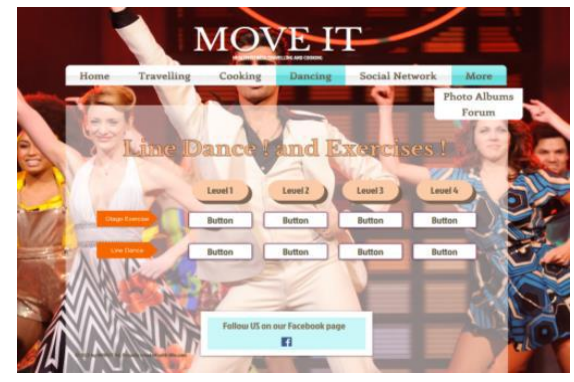

Fig.8a. Web/mobile exergaming homepage

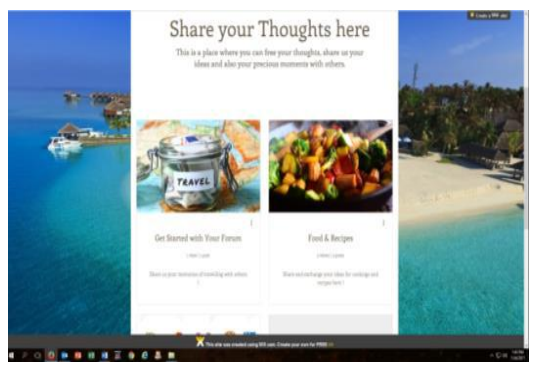

Fig. 8b. Web/mobile exergaming (forum page)

\section{CONCLUSION}

We have presented both youth studies and preliminary requirements analysis and adaptations for inclusive design. Hopefully, these platforms can serve as a mini resource and community engagement centre or meaningful activities for personal time -- for the youth, seniors and caregivers.

If all works well, to venture into collaboration with Arizona University and other interested universities to encourage meaningful interactions/ innovation from a knowledge management perspective, i.e., to explore resource-based and knowledge-based approaches to possibly also derive ontological relations applicable to knowledge base creation and personalized services. Focus will still be on design thinking, computational thinking, user experience and agile methodology.

\section{ACKNOWLEDGEMENT}

The first two projects are funded under Sunway University's internal grant (Feb-December 2016) whereas the latter two projects are funded by the Malaysian Fundamental Research Grant Scheme. Thanks to the IEEE for its vision of advancing technology for humanity, Scratch, the Learning Sciences community, Sunway University and Sunway University's capstone students, Chee-Ken Wong, Samuel Hong-Shan Low, Shanice WeiLing Chan and Sheng-Yee Guy, the Alzheimer's Disease Foundation of Malaysia, their very kind and supportive clients, head nurse and nurses, Multimedia University and Universiti Tunku Abdul Rahman for foundations which enabled these studies. 


\section{REFERENCES}

[1] K. Brennan and M. Resnick, "New frameworks for studying and assessing the development of computational thinking," Annual Meeting of the American Educational Research Association, Vancouver, Canada, 2012.

[2] J. Wing, "Computational thinking," Communications of the $A C M$, vol. 49, no. 3, pp. 33-35, 2006.

[3] C. S. Lee and K. D. Wong, "Discovering an Ontological Affective-Socio-Cognitive Co-Design Model: Towards a Symbiotic Context-Aware Recommender," International Conference on Cognition and Exploratory Learning in the Digital Age, October 24-26, 2015, Ireland.

[4] T. Brown, \& J. Wyatt. Design Thinking for Social Innovation, In Stanford Social Innovation Review, 2007, 3135.

[5] C. L. Dym, A. M Agogino, O. Eris, D. D. Frey and L. J. Leifer, Engineering Design Thinking, Teaching, and Learning, Journal of Engineering Education, vol. 94, issue 1, 2005, 103-120.

[6] J. Kolodner, P. K. Camp, D. Crismond, B. Fasse, J. Gray, J. Holbrook, S. Puntambekar, S. and M. Ryan, "Problem-based learning meets case-based reasoning in the middle-school science classroom: Putting Learning-by -design into practice," The Journal of the Learning Sciences, vol. 12, no. 4, pp. 495-547, 2003.

[7] C. S. Lee and K. D. Wong, "E-commerce Web design engineering: Towards discovery of innovational opportunities," IEEE International Conference on Advanced Learning Technologies, July 25-28, 2016, Austin, Texas.

[8] C. S. Lee and K. D. Wong, "An entrepreneurial narrative media-model framework for knowledge building and open co-design," IEEE SAI Computing, July 18-20, 2017, London, UK.

[9] T. Lindberg, C. Meinel, and R. Wagner, "Design thinking: A fruitful concept for IT development?" In Plattner, H., Christoph, M. and Leifer, L. J. Eds. Design thinking: Understand, improve, apply. Understanding innovation. Berlin, Heidelberg: Springer-Verlag, 2011.

[10] J. Edelman, and R. Currano, "Re-representation: Affordances of shared models in team-based design," In M. Christoph, and L. J. Leifer, Eds. Design thinking: understand, improve, apply. Understanding innovation. Berlin; Heidelberg: Springer-Verlag, 2011.

[11] J. M. Keller, What is motivational design? Retrieved 14th April, 2016. http://arcsmodel.com/Mot\%20dsgn\%20Mot\%20dsgn.htm

[12] J. Hamari, J. Koivisto, and H. Sarsa, "Does Gamification Work? - A Literature Review of Empirical Studies on Gamification," In Proceedings of the 47th Hawaii International Conference on System Sciences, Hawaii, USA, January 6-9, 2014.
[13] L. de-M arcos, A. Domínguez, J. Saenz-de-Navarrete, and C. Pagés, "An empirical study comparing gamification and social networking on e-learning," Computers \& Education, vol. 75, pp. 82-91, 2014.

[14] C. K. Wong and C. S. Lee, "A better understanding of how gamification can help improve digital lifestyles," International Conference on Virtual Systems and Multimedia, 2016, pp. 1-8.

[15] C. S. Lee and S. H. S. Low, "Developing interest to share and craft based on the Technology Acceptance Model", International Conference on Computational Thinking, 1013 July, 2017, Hong Kong.

[16] F. D. Davis, "Perceived usefulness, perceived ease of use and user acceptance of information technology," MIS Quarterly, vol. 13, no. 3, pp. 319-340, 1989.

[17] WHO. International Classification of Functioning, Disability and Health (ICF). New York: World Health Organization (WHO), 2001.

[18] M. M., Lai, S. Y., Lein, S. H. Lau, and M. L. Lai, "Determinants of aged friendly communities," Gerontechnology. vol. 13, no. 2, pp. 228, 2014.

[19] J. Zeisel, and P. Raia, "Non-Pharmacological Treatment for Alzheimer's disease: A M ind-Brain Approach", American Journal of Alzheimer's Disease \& Other Dementias, vol. 15, no. 6, pp. 331-340, 2000.

[20] S. Saczynski, I. A. Pfeifer, K. Masaki, E. S. Korf, D. Laurin, and L. White, "The effect of social engagement on incident dementia: The Honolulu-Asia Aging Study," American Journal of Epidemiology, vol. 163, no. 5, pp. 433-40, 2006.

[21] D. Brooker, Person-centred Dementia Care: Making Services Better, Jessica Kingsley Publishers, 2007.

[22] C. S. Lee and K. D. Wong, "Design thinking and semiotics to increase socio-cognitive-affective engagement: An inclusive design human factors case study," International Conference on Industrial Engineering and Engineering Management, December 10-13, 2017, Singapore.

[23] R. Koster. Theory of fun for game design. O'Reilly Media, 2004.

[24] C. S. Lee, S. W. L. Chan and S. Y. Guy, "Socially-enhanced variants of mobile bingo game: Towards personalized cognitive and social engagement among seniors", International Conference on Soft Computing, Intelligent System and Information Technology, September 26-29, Bali, Indonesia.

[25] S. Y. Guy and C. S. Lee, "Web and mobile-based augmented reality to encourage exercise," Unpublished capstone project, Sunway University. 2017. 